\title{
Authors' reply: Outbreak of a new measles B3 variant in the Roma/Sinti population with transmission in the nosocomial setting, Italy, November 2015 to April 2016
}

A Filia ${ }^{1}$, M Faccini ${ }^{2}$, A Amendola ${ }^{3}$, $\mathrm{F}_{\text {Magurano }}{ }^{4}$, on behalf of the authors of the original article 5

1. Infectious Diseases Epidemiology Unit, Istituto Superiore di Sanità, Rome, Italy

2. Health Protection Agency, Metropolitan Area of Milan, Milan, Italy

3. Department of Biomedical Sciences for Health, University of Milan, Milan, Italy

4. National Reference Laboratory for Measles and Rubella, Istituto Superiore di Sanità, Rome, Italy

5. http://www.eurosurveillance.org/ViewArticle.aspx?Articleld=22481

Correspondence: Antonietta Filia (antonietta.filia@iss.it)

Citation style for this article:

Filia A, Faccini M, Amendola ,A, Magurano F, on behalf of the authors of the original article. Authors' reply: Outbreak of a new measles B3 variant in the Roma/ Sinti population with transmission in the nosocomial setting, Italy, November 2015 to April 2016. Euro Surveill. 2016;21(27):pii=30276. DOI: http://dx.doi. org/10.2807/1560-7917.ES.2016.21.27.30276

Article submitted on 28 June 2016 / accepted on 28 June 2016 / published on o7 July 2016

To the editor: The letter by Monasta and Knowles regarding our recent paper allows us to clarify some important points $[1,2]$. As they pointed out, our article was picked up by various, mainly local, newspapers, with sometimes alarming titles depicting the Roma population as responsible for transmitting measles to the majority population. This is quite unfortunate and was clearly not our intention. We stated in the article that the identified strain was first introduced in Como and Rimini in August 2015, i.e. some time before the start of the described outbreak in November, and that the outbreak in the Roma settlement did not spread extensively in the community. Cases then occurred in the nosocomial setting, especially among healthcare workers, another undervaccinated group [3].

Besides the Roma and healthcare workers, analyses of Italian national surveillance data has shown that pockets of undervaccinated populations also exist among young adults born in the 1980 s and 1990 s when uptake of measles vaccine was very low and the second dose had not yet been introduced [4]. The Roma, therefore, represent only one of several undervaccinated population groups for whom stronger vaccination efforts are needed. Finally, we pointed out that in order to reach elimination, it will be necessary to improve not only coverage among hard-to-reach populations but the overall national vaccination coverage, which is below the 95\% target (86.7\% in 2014) [5]. Monasta and Knowles call for compulsory vaccination. However, high coverage can be achieved through other strategies, such as strengthening routine immunisation systems, improving communication, information and advocacy, and providing targeted supplementary immunisation activities to age cohorts or population groups that have inadequate levels of immunity [6].
We agree with Monasta and Knowles that sociocultural aspects are extremely relevant in any analysis of poor access to health services and/or of low vaccination uptake among the Roma. However, analysing the complex determinants of health and low vaccination uptake among this population group was beyond the scope of our paper and we referred to a recent report by the European Centre for Disease Prevention and Control, describing barriers causing low measles-mumpsrubella (MMR) vaccination among hard-to-reach population groups in Europe, including Roma [7]. The barriers among the Roma are many and include reduced access to healthcare, poor socioeconomic status/poverty, geographical isolation/poor housing and sanitary conditions, low levels of education/illiteracy, administrative barriers, discrimination and cultural differences [7]. Therefore, to achieve high MMR vaccination among the Roma population, the wider determinants of health must be addressed, including marginalisation as discussed by Monasta and Knowles.

The communities living in the camps affected by the measles outbreaks in Milan are of Roma ethnicity and mainly of Romanian nationality. The camps in which they live are organised settlements, run by the municipality, and hosting Roma and migrants facing social and/or housing emergencies. Although the Roma living in these camps are registered with the national healthcare system (and are therefore entitled to and have access to free vaccination services) and the children attend school, they are mobile communities that frequently move from place to place, within national boundaries or back to their country of origin. Vaccinations are actively offered to children living in the settlements, by inviting families to the local vaccination centres. This is done with the help of educators 
who are present in the settlements daily and whose role is to facilitate integration of the Roma into the community. Unfortunately, there is a lack of data on vaccination uptake. During the described outbreak, uptake was not ideal as only 52 of 246 persons present in the settlements accepted to be vaccinated despite being invited to the vaccination centre.

In addition to routine vaccination, a specific project, financed by the Italian Ministry of Health and aimed at improving access to preventive services and promoting vaccinations among Roma children was carried out in 2013-14. The project was conducted in several Italian cities, including Milan, and involved the use of cultural mediators, distribution of information in Romani, and training of health and social workers to improve their understanding of Roma issues [8]. Results are pending.

Improving vaccination uptake among the Roma is a challenge but examples of successful programmes show that it is feasible [7]. Methods to monitor MMR vaccination coverage within this population need to be implemented, to measure progress and prevent outbreaks [7].

\section{Conflict of interest}

None declared.

Authors' contributions

AF drafted the manuscript. MF, AA and FM critically revised the manuscript. All authors of the original paper approved the final manuscript.

\section{References}

1. Monasta L, Knowles. Letter to the editor: Outbreak of a new measles B3 variant in the Roma/Sinti population with transmission in the nosocomial setting, Italy, November 2015 to April 2016. Euro Surveill. 2016;21(26):30235. http://dx.doi. org/10.2807/1560-7917.ES.2016.21.26.30273.

2. Filia A, Amendola A, Faccini M, Del Manso M, Senatore S, Bianchi $S$, et al. Outbreak of a new measles $B_{3}$ variant in the Roma/Sinti population with transmission in the nosocomial setting, Italy, November 2015 to April 2016. Euro Surveill. 2016;21(20):30235. DOI: 10.2807/1560-7917. ES.2016.21.20.30235 PMID: 27240004

3. Filia A, Bella A, Cadeddu G, Milia MR, Del Manso M, Rota $M C$, et al. Extensive nosocomial transmission of measles originating in cruise ship passenger, Sardinia, Italy, 2014. Emerg Infect Dis. 2015;21(8):1444-6. DOI: 10.3201/ eid2108.141105 PMID: 26196266

4. Filia A, Bella A, Rota M, Tavilla A, Magurano F, Baggieri $M$, et al. Analysis of national measles surveillance data in Italy from October 2010 to December 2011 and priorities for reaching the 2015 measles elimination goal. Euro Surveill. 2013;18(20):20480. Available from: http://www. eurosurveillance.org/ViewArticle.aspx?Articleld=20480PMID: 23725868

5. Italian Ministry of Health. Vaccinazioni dell'età pediatrica - Coperture vaccinali. [Vaccination coverage in paediatric age groups]. Rome: Ministero della Salute. [Accessed: 27 June 2016]. Italian. Available from: http://www. salute.gov.it/portale/documentazione/p6_2_8_3_1. jsp?lingua=italiano\&id $=20$

6. European Centre for Disease Prevention and Control (ECDC). Implementing the ECDC action plan for measles and rubella. Stockholm: ECDC; 2014 . Available from: http://ecdc.europa.eu/ en/publications/Publications/measles-rubella-implementing action-plan.pdf
7. European Centre for Disease Prevention and Control (ECDC). Review of outbreaks and barriers to MMR vaccination coverage among hard-to-reach populations in Europe. Stockholm: ECDC; 2013. Available from: http://ecdc.europa.eu/en/publications/ Publications/MMR-vaccination-hard-to-reach-populationreview-2013.pdf

8. Progetto troVARSI (Vaccinazioni Rom e Sinti in Italia) [Trovarsi project (Vaccination of Roma and Sinti in Italy]. Rome: National Institute for Health Migration and Poverty; 2013. Italian. Available from: http://www.inmp.it/index.php/ita/Progetti/ Progetto-troVARSI-Vaccinazioni-Rom-e-Sinti-in-Italia

License and copyright

This is an open-access article distributed under the terms of the Creative Commons Attribution (CC BY 4.0) Licence. You may share and adapt the material, but must give appropriate credit to the source, provide a link to the licence, and indicate if changes were made.

This article is copyright of the authors, 2016. 